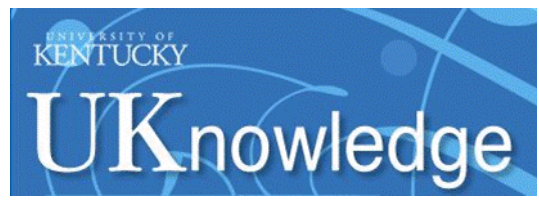

University of Kentucky

UKnowledge

\title{
Torque Production Capability of Axial Flux Machines with Single and Double Rotor Configurations
}

\author{
Narges Taran \\ University of Kentucky, narges.taran@uky.edu \\ Greg Heins \\ Regal Beloit Corporation, Australia \\ Vandana Rallabandi \\ University of Kentucky, vandana.rallabandi@uky.edu \\ Dean Patterson \\ Regal Beloit Corporation, Australia \\ Dan M. Ionel \\ University of Kentucky, dan.ionel@uky.edu
}

Follow this and additional works at: https://uknowledge.uky.edu/peik_facpub

Part of the Power and Energy Commons

Right click to open a feedback form in a new tab to let us know how this document benefits you.

\section{Repository Citation}

Taran, Narges; Heins, Greg; Rallabandi, Vandana; Patterson, Dean; and Ionel, Dan M., "Torque Production Capability of Axial Flux Machines with Single and Double Rotor Configurations" (2018). Power and Energy Institute of Kentucky Faculty Publications. 35.

https://uknowledge.uky.edu/peik_facpub/35

This Conference Proceeding is brought to you for free and open access by the Power and Energy Institute of Kentucky at UKnowledge. It has been accepted for inclusion in Power and Energy Institute of Kentucky Faculty Publications by an authorized administrator of UKnowledge. For more information, please contact UKnowledge@lsv.uky.edu. 


\title{
Torque Production Capability of Axial Flux Machines with Single and Double Rotor Configurations
}

\author{
Digital Object Identifier (DOI) \\ https://doi.org/10.1109/ECCE.2018.8557818
}

\section{Notes/Citation Information}

Published in 2018 IEEE Energy Conversion Congress and Exposition (ECCE).

(C) 2018 IEEE Copyright Notice. "Personal use of this material is permitted. Permission from IEEE must be obtained for all other uses, in any current or future media, including reprinting/republishing this material for advertising or promotional purposes, creating new collective works, for resale or redistribution to servers or lists, or reuse of any copyrighted component of this work in other works."

The document available for download is the authors' manuscript version that is accepted for publication. The final published version is copyrighted by IEEE and will be available as: N. Taran, G. Heins, V. Rallabandi, D. Pattersonand D. M. Ionel, "Torque Production Capability of Axial Flux Machines with Single and Double Rotor Configuration," Rec. 2018 IEEE Energy Conversion Congress and Exposition (ECCE), Portland, OR, Sept 2018, 6p. 


\section{Torque Production Capability of Axial Flux Machines with Single and Double Rotor Configurations}

\author{
Narges Taran \\ SPARK Lab, ECE Dept. \\ University of Kentucky \\ Lexington, KY, USA \\ narges.taran@uky.edu
}

\author{
Greg Heins \\ Regal Beloit Corp. \\ Research and Development \\ Rowville, VIC, Australia \\ greg.heins@ regalbeloit.com
}

\author{
Vandana Rallabandi \\ SPARK Lab, ECE Dept. \\ University of Kentucky \\ Lexington, KY, USA \\ vandana.rallabandi@uky.edu
}

\author{
Dean Patterson \\ Regal Beloit Corp. \\ Research and Development \\ Rowville, VIC, Australia \\ dean.patterson@ regalbeloit.com
}

\author{
Dan M. Ionel \\ SPARK Lab, ECE Dept. \\ University of Kentucky \\ Lexington, KY, USA \\ dan.ionel@uky.edu
}

\begin{abstract}
Axial flux PM (AFPM) machines are used particularly in applications requiring a compact structure. Their disc shape topology and axial air-gap have lead to a variety of configurations including two popular ones: the yokeless and segmented armature (YASA), and the single-stator singlerotor or single sided machine. In this study, a comprehensive comparative analysis of these configurations is conducted at different magnetic and electric loadings. It is found that at lower loadings, typically employed for air-cooled machines, the torque/ampere characteristics of the YASA machine are almost identical to those of a single sided machine constructed with half the magnet volume. On the other hand, the single sided machine outperforms the YASA machine when the magnet volumes in both machines are maintained equal. However, for higher electric loadings, the torque/ampere characteristics of the YASA machine droop significantly less than those of the single sided machine. The paper includes analytical estimations which are verified with experimentally validated FEA simulations. In addition, the impacts of the armature reaction on saturation and the magnetic flux linkage in both machines is also explored.
\end{abstract}

Index Terms-Axial flux permanent magnet, yokeless and segmented armature, YASA, armature reaction, power factor.

\section{INTRODUCTION}

Axial flux permanent magnet (AFPM) machines are acclaimed for their high efficiency, torque density, and compact structure. The disc shape topology has opened up many possibilities for variants, where their counterparts in the radial air-gap form involve a high degree of mechanical complexity [1]. One such variant is the double outside rotor machine with a yokeless and segmented armature (YASA) between the rotors [2], [3]. This configuration can be viewed as an axially mirrored and duplicated version of a single sided AFPM machine without the stator yoke.
YASA machines exploit and apply the benefits of fractional slot concentrated windings to the TORUS-NS machine [3], which was originally conceived and studied with a distributed winding. The fractional slot concentrated winding facilitates the modular stator teeth construction which results in a higher fill factor, reduced mutual inductance between phases (thereby improving the phase independency and fault tolerance), a higher efficiency, and compactness [4].

The mechanical challenges of the YASA topology remain its major drawbacks and are twofold. Firstly, if the segmented stator sections are to be made of laminated steel and stacked radially, they should increase in circumferential width from the inner to the outer radius. That is, to carry the axially directed flux, each single lamination must be differently shaped. This can be addressed by methods such as punching reduced width laminations, or using soft magnetic composite (SMC) materials [4]-[6]. The second drawback is the difficulty of holding the individual stator segments in place while maintaining a balanced air-gap [7]. This can be resolved by utilizing annular plates containing openings the same size as the shoe of the stator segments [6], or by incorporating ring holders [4].

A comparative study conducted on transverse flux, radial flux, and YASA machines with identical dimensions and the same PM mass concluded that the transverse flux topology performs better when a low speed, a high torque, and small electric loadings are desired. However, in case of limited axial lengths, YASA is found to be superior [8]. In another study, YASA, single sided, and TORUS machines were compared [9], showing that the torque density $\left(\mathrm{Nm} / \mathrm{m}^{3}\right)$ of YASA is higher than the others at the rated specifications of an electric vehicle.

The literature lacks a comprehensive comparative study across a wide range of loadings. This paper conducts such a study for the YASA and single sided machines. The torque 


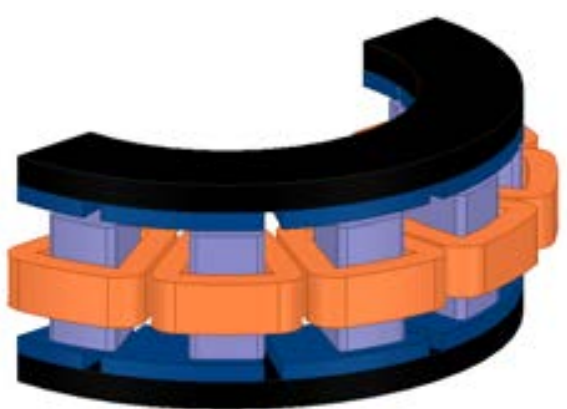

(a)

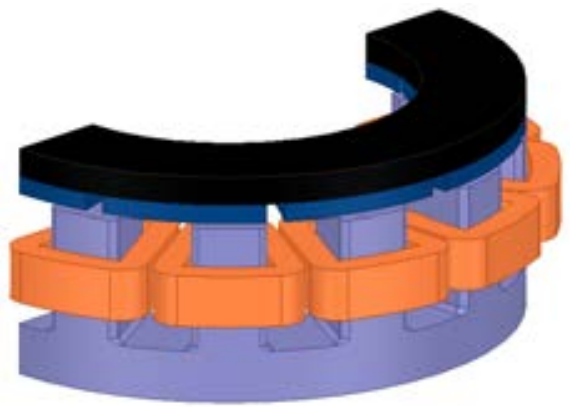

(b)

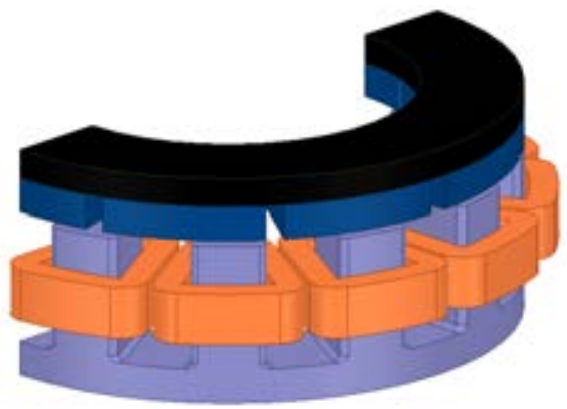

(c)

Fig. 1. The 3D FEA parametric model of three topologies to be studied; (a) the YASA structure, (b) the single sided machine with half the total magnet volume as the YASA (S1M), and (c) the single sided machine with the same total magnet volume as the YASA (S2M).

constant, power factor, and overload capability are compared within the same physical envelope.

\section{Specifications of the Topologies Compared}

The comparative study is conducted between three topologies: 1) a YASA structure, 2) a single sided machine with half the total magnet volume of the YASA machine (S1M), and 3) a single sided machine with the same total magnet volume as the YASA structure (S2M). The parametric models are presented in Fig. 1. They all have 10 poles and 12 open slots. The axial length, active diameter, slot depths and copper volume are maintained constant for all three machines. The rotor back iron lengths are identical while the stator yoke thickness is adjusted based on mechanical limitations and a constrained total axial length. The stator employs SMC in all cases.

Comparative studies with both ferrite (remanence of $0.4 \mathrm{~T}$ ) and rare earth magnets (remanence of $1.23 \mathrm{~T}$ ) are conducted in order to reach a general conclusion within a wide range of magnetic loading. All analyses are performed with 3D FEA. An example FEA result showing 3D flux lines is presented in Fig. 2. A non-overlapping concentrated winding is used for its shorter end turns and lower copper mass. The shorter end turns are particularly beneficial in case of axial flux machines which generally have larger diameters compared to machines with radial air-gaps. A double layer winding is utilized in order to reduce the coil width and achieve a larger active diameter compared to the single layer windings.

\section{AnAlytical Evaluation}

The electromagnetic torque of an AFPM machine with a pure q-axis current excitation, i.e. $i_{d}=0$, can be estimated from

$$
T_{e}=\frac{3}{2} \frac{p}{2} \lambda_{d} i_{q} ; \quad \lambda_{d}=\lambda_{m o}-L_{e} \cdot i_{q}
$$

where $p$ is the number of poles; $\lambda_{d}$, the d-axis flux linkage; $\lambda_{m o}$, the open circuit flux produced by the magnets; and $L_{e}$ is an equivalent inductance to capture the drop in d-axis flux linkage due to the q-axis current [10]. Figure 3 plots $\lambda_{d}$ versus

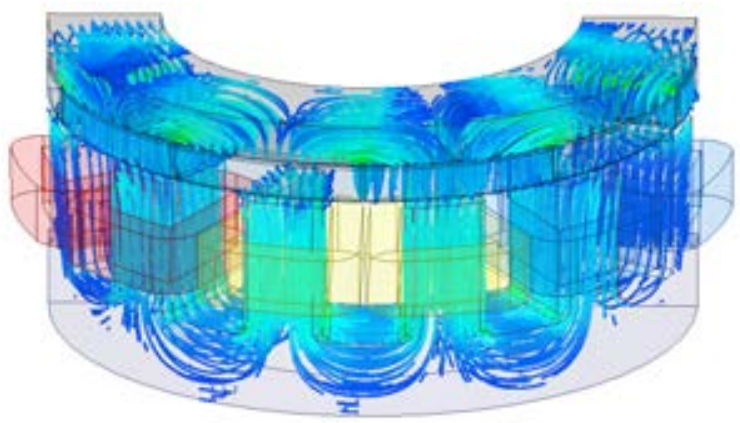

Fig. 2. The 3D FEA result, showing flux lines of the single sided AFPM machine (S2M).

$i_{q}$. It can be seen that this drop is fairly linear and the slope can be represented by $L_{e}$ as

$$
L_{e}=\frac{\Delta \lambda_{d}}{\Delta i_{q}} .
$$

$L_{e}$ has a larger value for machines with a higher saturation level, as shown in Figs. $4 \mathrm{a}$ and $4 \mathrm{~b}$, resulting in a sharper decline in the d-axis flux in the load operation. This results in non-linear torque-current characteristics, which will be further discussed in section VI.

The magnet flux, $\lambda_{m o}$, can be estimated as [11]

$\lambda_{m o}=\frac{2}{\pi} k_{w 1} N_{t} k_{v g} \alpha_{i} B_{g o} \tau_{p} L_{F e} ; \quad B_{g o}=\frac{B_{r}}{\frac{1}{k_{\sigma}}+\frac{\mu_{m r} k_{c} k_{s o} g}{L_{p m}}}$,

where $k_{w 1}$ is the fundamental winding factor; $N_{t}$, the number of turns per phase; $k_{v g}$, the ratio between the amplitude of the fundamental wave and the average value of the air-gap flux density; $B_{g o}$, the peak value of the open-circuit flux density; $\tau_{p}$, the pole pitch; $L_{F e}$, the inner diameter subtracted from the outer diameter in case of an axial air-gap machine; $B_{r}$, the remanence of the magnets; $L_{p m}$, the magnet thickness in the direction of magnetization; $\alpha_{i}$, the pole-arc to pole-pitch ratio; $g$, the air-gap length; $k_{c}$, Carter's coefficient; $\mu_{m r}$, the relative permeability of the PM; $k_{s o}$, the d-axis saturation factor in the open-circuit operation; and $k_{\sigma}$ is the leakage coefficient. 


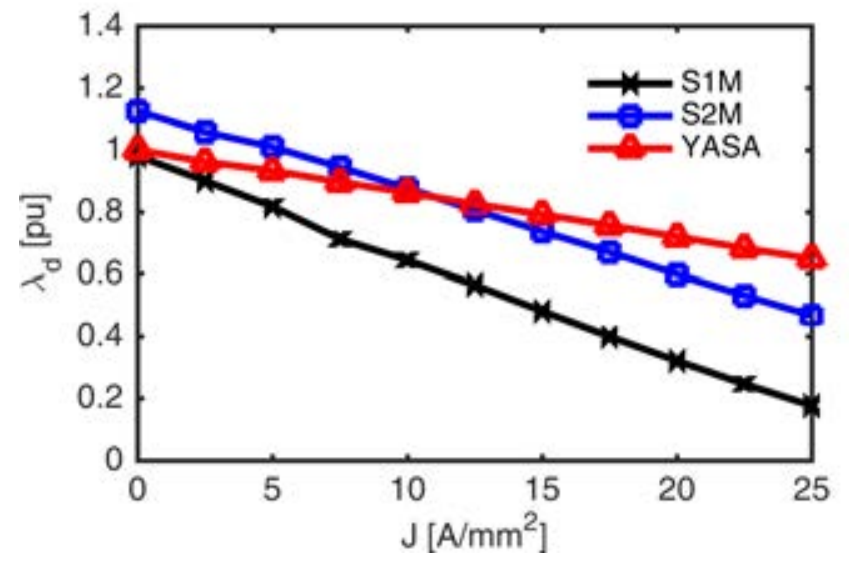

Fig. 3. D-axis flux linkage at different q-axis currents, per-unitized based on $\lambda_{d}$ of the YASA machine at open-circuit. The reduction in $\lambda_{d}$ due to $i_{q}$ is considerably higher for the single sided machines due to greater saturation.

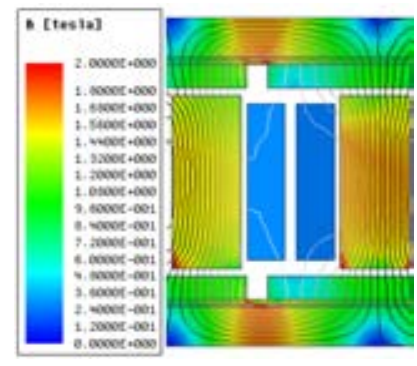

(a)

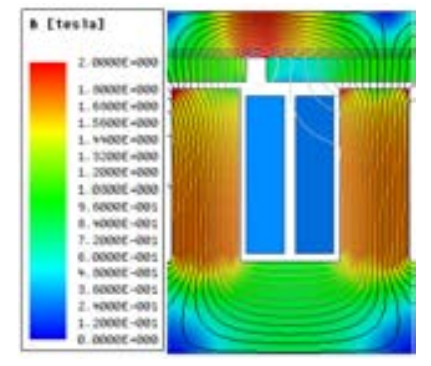

(b)
Fig. 4. Flux density distribution with pure q-axis excitation for (a) the YASA machine, and (b) the S1M machine, at the current density of $25 \mathrm{~A} / \mathrm{mm}^{2}$. The stator teeth and rotor core operate in saturation, which explains the reduction in d-axis flux at high q-axis currents.

Based on (3), for an unsaturated machine with negligible leakage and fringing $\left(k_{\sigma}, k_{c}\right.$, and $\left.k_{s o}=1\right), \lambda_{m o}$ is proportional to the ratio of the total magnet thickness to the total electromagnetic air-gap, i.e. $\frac{L_{p m}}{\mu_{m r} \cdot g+L_{p m}}$. The S1M machine has half the air-gap and half the magnet thickness of the YASA machine, while the S2M machine has half the mechanical air-gap of the YASA for the same overall magnet thickness. Therefore, $\frac{L_{p m}}{\mu_{m r} \cdot g+L_{p m}}$ is identical for S1M and YASA, while it is higher for S2M. This leads to a higher $\lambda_{m o}$ for S2M and comparable values for YASA and S1M, as observed in Fig. 3 ( $\lambda_{d}$ at $\left.i_{q}=0\right)$.

Another phenomenon affecting torque production, particularly at higher currents, is the armature reaction which strongly influences the displacement power factor. The stator inductance, $L_{s}\left(L_{q}=L_{d}=L_{s}\right)$, may be estimated by

$$
L_{s}=\frac{m \mu_{0}\left(k_{w 1} N_{t}\right)^{2} \tau_{p} L_{F e}}{\pi^{2} p\left(k_{c} g+\frac{L_{p m}}{\mu_{m r}}\right)} \cdot \frac{1}{k_{s d}},
$$

where $m$ is the number of phases, and $k_{s d}$ the saturation coefficient with values larger than 1 for higher saturation levels. A larger electromagnetic air-gap results in a lower inductance, and thus a smaller armature reaction and a higher power factor. Therefore, the armature reaction effect would be lowest in case of the YASA machine and highest for the S1M. This is to the YASA's advantage, particularly at higher loadings.

A common argument is that the eliminated stator yoke in the YASA machine provides extra space for the stator and copper, resulting in a higher torque within the same volume. Nevertheless, not all of this space can be used by copper since some room must be provided for the second rotor disc. However, such an argument may be more credible in cases where the stator employs a thicker yoke for mechanical and/or electromagnetic reasons.

The torque production principles can also be explained with shear stress and the air-gap surface area [1]. The electromagnetic torque of any electric machine can be defined as the product of the electromagnetic force, $F$, and the radius:

$$
T_{e}=F r ; F=\sigma a_{a} ; \sigma=B A,
$$

where $r$ is the radius; $\sigma$, the electromagnetic air-gap shear stress; $a_{a}$, the air-gap area; $B$, the magnetic loading; and $A$, the electric loading defined as the ampere-turns per unit of periphery. Although in the YASA configuration $a_{a}$ is twice that of the single sided AFPM machine, $A$ and consequently $F$ for each air-gap is reduced by half. Therefore, doubling the air-gap surface area in the YASA structure does not double the torque.

\section{Design of EXPERIMENTS AND SENSITIVITy} ANALYSIS

The primary intent of the sensitivity analysis in this case is to study the impact of the loadings on the performance indices. To perform a systematic study, the performance indices (responses) and their corresponding variables (factors) are selected. Then, several designs are selected employing the design of experiments methodology. These designs, which best represent the relation between the responses and factors, are studied with 3D FEA evaluations. The sensitivity analysis is executed by a fitting a regression polynomial function. The factors with very small coefficients can be regarded as noise and their effect is neglected.

The responses selected are the electromagnetic torque, the stator core losses, and the displacement power factor. For each response, 7 variables are selected, including: the current density, $J$; the stator yoke to the total axial length ratio, $k_{s y}$; the rotor yoke to the total axial length ratio, $k_{r y}$; the magnet thickness to the total axial length ratio, $k_{p m}$; the slot depth to the total axial length ratio, $k_{s d}$; and the split ratio defined as the inner to the outer diameter ratio. Figure 5 represents the results, where positive values indicate a proportional increase in the response when the factor is increased, while negative values represent a proportional decrease. Larger values indicate a stronger sensitivity.

The study is conducted for machines with both ferrite and Neodymium magnets. The magnet volume is identical in all cases. Some considerable outcomes of the sensitivity analysis, demonstrated in Fig. 5, are as follows: 
1) An increase in the ampere-turns improves the electromagnetic torque more significantly in the YASA compared to the single sided machine, which is due to to the YASA's lower armature reaction.

2) The stator and rotor yoke thicknesses have negligible effects, indicating that the yokes are not saturated within the studied range.

3) In case of an increased slot depth, the improvement in torque production is considerable only in the YASA machine. This can be attributed to the increased flux leakage in the single sided machines with deeper slots.

4) Due to the larger volume of the stator core in the single sided machines and the larger armature reaction, the effect of the current on core loss is higher.

5) The reduction in the displacement power factor due to the increased current density is more significant for the single sided machine. This is due to smaller armature reaction of the YASA machine.

6) Higher magnetic loading causes less reduction in the displacement power factor at overload operation. This is in line with expectations, due to the smaller per unit reactance with $\mathrm{NdFeB}$ magnets than with ferrites.

\section{Performance Comparison at Low Magnetic and ELECTRIC LOADINGS}

The performance of the three topologies at a current density of $5 \mathrm{~A} / \mathrm{mm}^{2}$ with ferrite and $\mathrm{NdFeB}$ magnets has been investigated. Based on analytical evaluations, it was expected that for such current densities, the machines with a higher ratio of the overall magnet thickness to the effective air-gap, have a higher specific torque. Table I shows that for both magnet materials, YASA has the lowest torque and S2M the highest, as expected.

To examine the effect of increased number of air-gaps on shear stress and torque, a $4^{\text {th }}$ configuration is studied, $\mathrm{S} 2 \mathrm{M}_{2 a g}$, which is the same as S2M except for the additional air-gap on the other side of the stator, Fig. 8d. The additional airgap reduces the torque constant such that $\mathrm{S}_{2} \mathrm{M}_{2 a g}$ and YASA almost have the same torque, at this loading.

The stators are made of SMC material. Therefore, the stator core loss comprises mainly hysteresis losses. The eliminated stator yoke significantly reduces core losses of the YASA machine. In order to compare the stator core losses for S1M and S2M machines it should be considered that the air-gap

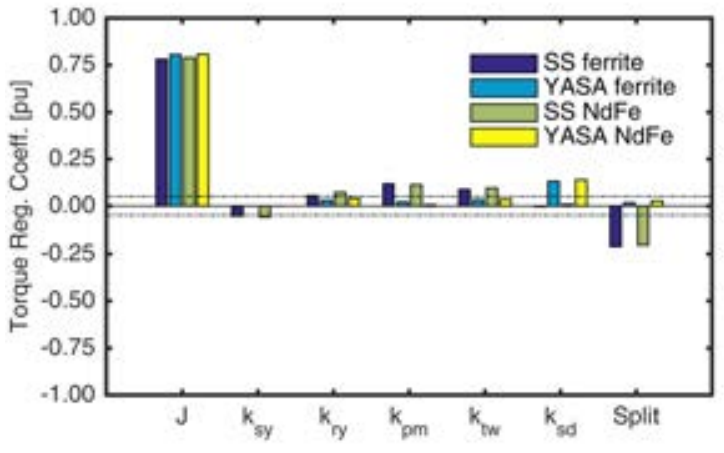

(a)

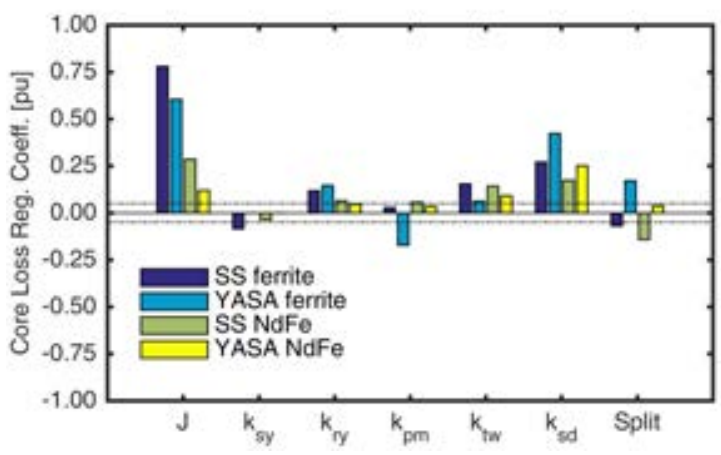

(b)

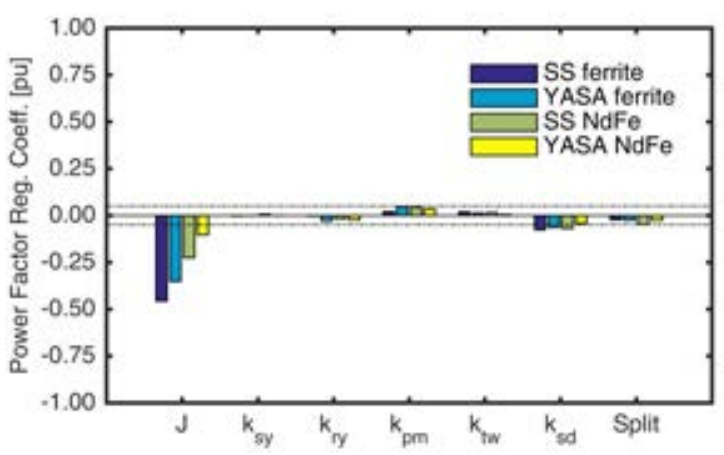

(c)

Fig. 5. The sensitivity analysis of the (a) electromagnetic torque, (b) stator core loss, and (c) power factor for single sided and YASA topologies. The horizontal dashed lines distinguish the insignificant factors with maximum effect being less than $5 \%$ variation in the response, within the studied range.

TABLE I

THE PERFORMANCE OF THE YASA, S1M, AND S2M TOPOLOGIES AT THE CURRENT DENSITY OF $5 \mathrm{~A} / \mathrm{mm}^{2}$. THE COPPER LOSSES ARE EQUAL WITH IDENTICAL COILS AND WINDING STRUCTURE. THE LOSSES ARE PER-UNITIZED BASED ON S2M TOPOLOGY WITH FERRITE MAGNETS. S2M $2 a g$ IS SIMILAR TO S2M EXCEPT THAT IT HAS AIR-GAPS AT BOTH SIDES OF THE STATOR.

\begin{tabular}{ll|rrrr|rrrr}
\hline & & \multicolumn{4}{|c|}{ ferrite magnets } & \multicolumn{4}{c}{ NdFe magnets } \\
& & YASA & S1M & S2M & S2M $_{2 a g}$ & YASA & S1M & S2M & S2M $_{2 a g}$ \\
\hline Torque constant & {$[\mathrm{Nm} / \mathrm{A}]$} & 0.23 & 0.25 & 0.30 & 0.22 & 0.60 & 0.66 & 0.77 & 0.60 \\
Stator core loss & {$[\mathrm{pu}]$} & 0.6 & 1.3 & 1.0 & 0.7 & 3.7 & 5.1 & 6.6 & 4.0 \\
Bearing loss & {$[\mathrm{pu}]$} & 0.5 & 1.0 & 1.0 & 0.5 & 0.5 & 1.0 & 1.0 & 0.5 \\
Power factor & 0.97 & 0.83 & 1.00 & 0.93 & 0.98 & 0.99 & 1.00 & 0.99 \\
\hline
\end{tabular}




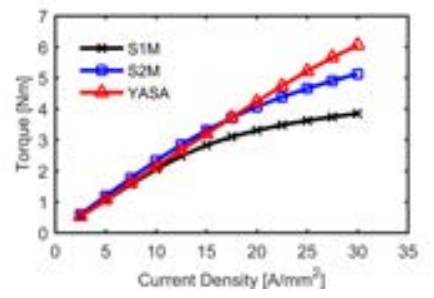

(a)

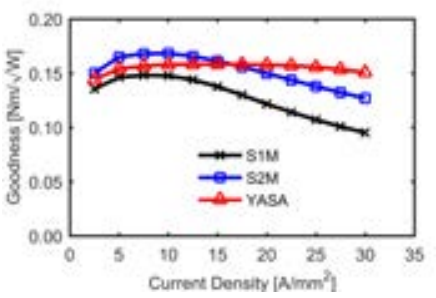

(c)

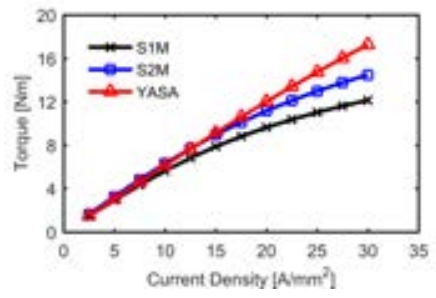

(b)

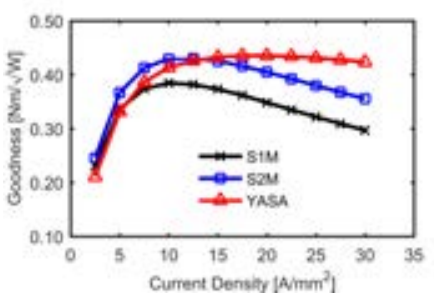

(d)
Fig. 6. The torque production of YASA, S1M and S2M topologies with slot depth of $\mathcal{L}$. (a) electromagnetic torque with ferrite magnets, and (b) with Neodymium magnets, (c) goodness with ferrite magnets, and (d) with Neodymium magnets.

flux density for S2M is larger. Utilizing ferrite magnets the stator core loss of S1M is greater than S2M, while with NdFe magnets S2M has a higher stator loss. The bearing loss for the single sided motor with a single air-gap is greater due to the increased axial load and the larger bearings consequently required.

The power factor of the S1M structure is the lowest which was expected due to its high per unit inductance. Comparing the power factor for YASA and S2M, at low loadings S2M is slightly superior due to higher back EMF. Based on analytical evaluation and Fig. 5c, it is expected that power factor reduction at higher loading for the YASA machine is less steep, resulting in better performance compared to S2M.

\section{OVERLOAD CAPABILITY AND EXPERIMENTAL VALIDATION}

The torque production and loss of the machines are evaluated at higher magnetic and electric loadings using 3D FEAs. In previous section it was shown that at lower loadings, the torque constant is the highest for S2M, followed by S1M, and then the YASA. In this section, it is found that at higher loadings, the situation changes, Figs. 6 and 7 .

Figure $6 \mathrm{a}$ and $6 \mathrm{~b}$ represent the torque at different currents with ferrite and rare earth magnets. The torque produced by S1M at higher currents declines very quickly because of saturation at very high loads. S2M remains slightly better than YASA for a wider range until YASA produces more torque, at very high loadings.

The torque-ampere turn characteristics of the single sided machine, start to bend at smaller currents as compared with the YASA. This indicates that the saturation of stator core of single sided machine happens at smaller currents. Therefore,

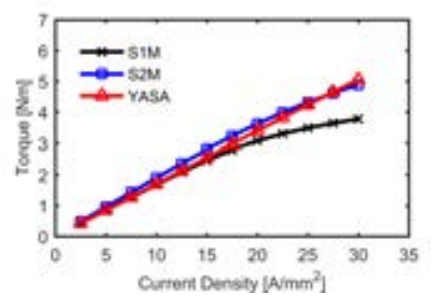

(a)

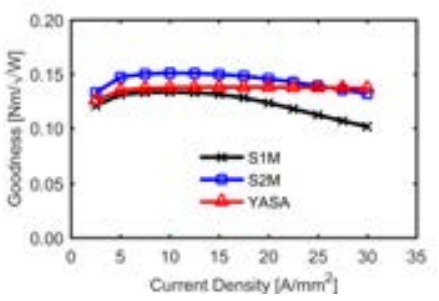

(c)

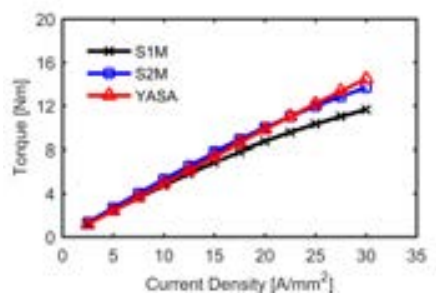

(b)

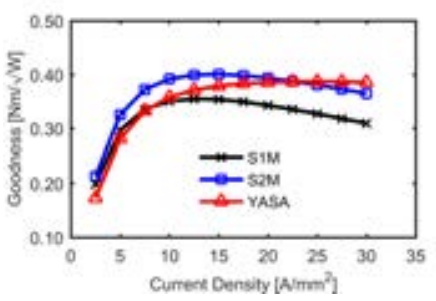

(d)
Fig. 7. The torque production of YASA, S1M and S2M topologies with $20 \%$ slot depth reduction compared to Fig. 6, i.e., $0.8 \cdot \mathcal{L}$. (a) electromagnetic torque with ferrite magnets, and (b) with Neodymium magnets, (c) goodness with ferrite magnets, and (d) with Neodymium magnets.

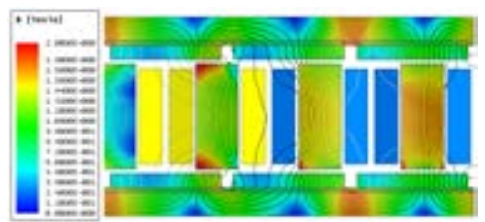

(a)

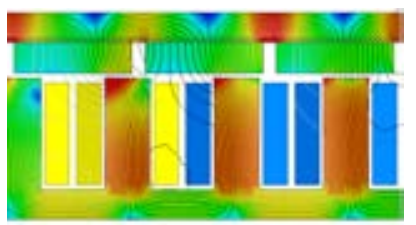

(c)

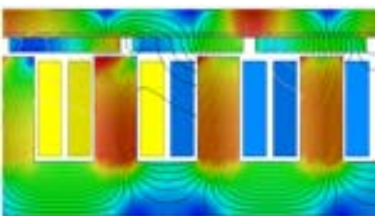

(b)

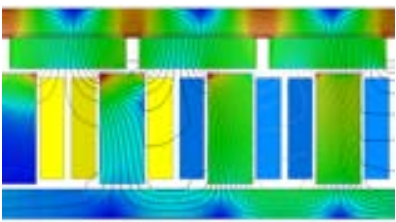

(d)
Fig. 8. Flux density distribution at high magnetic and electric loading, current density of $25 \mathrm{~A} / \mathrm{mm}^{2}$ with Neodymium magnets. Figure (d) and (c) are similar except for an additional air-gap in the latter.

the d-axis flux linkage declines more, shown in Fig. 3. The lower saturation of the YASA machine can be seen from the flux density distribution plots in Fig. 8.

The single sided machines have a higher stator core loss due to higher saturation and volume of the stator core. In order to include losses in the comparison, goodness defined as $\frac{\text { Torque }}{\sqrt{\text { Losses }}}$ is plotted, Fig. 6c and 6d. The goodness of the single sided topologies at higher loads declines more significantly as compared with the YASA.

Based on the sensitivity analysis in Fig. 5a, increased slot area in the axial direction (slot depth, $k_{s d}$ ) enhances torque production of the YASA topology more significantly than the single sided. This may be due to the flux leakage that is likely 

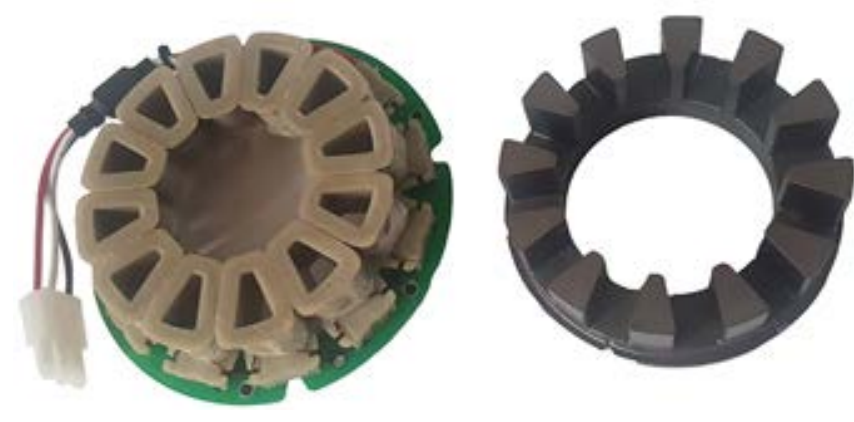

(a)
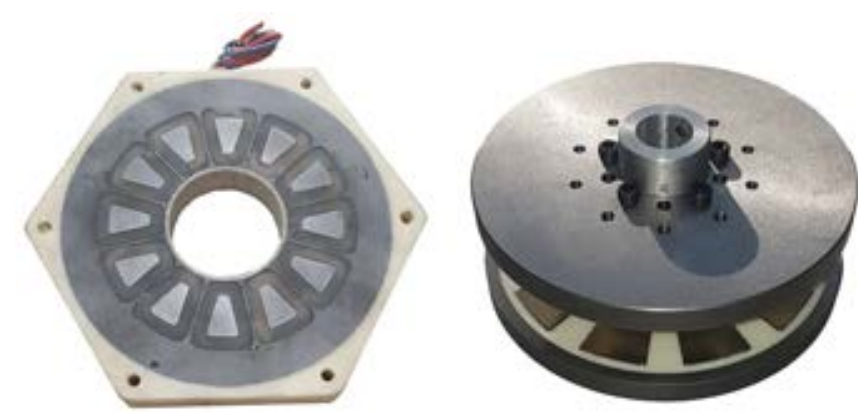

(b)

Fig. 9. (a) The S1M machine and (b) the YASA machine employed for experimental validation of the study.

TABLE II

THE EXPERIMENTAL VALIDATION OF 3D FEA MODELS FOR BACK EMF CONSTANT [V/RAD.S]. ALL MACHINES EMPLOY NDFE MAGNETS.

\begin{tabular}{lrr}
\hline & \multicolumn{2}{c}{ Back EMF Constant } \\
& 3D FEA & Measurement \\
\hline YASA & 0.28 & 0.29 \\
S1M & 0.27 & 0.29 \\
S2M & 0.32 & 0.34 \\
\hline
\end{tabular}

to impact the single sided machines more than the YASA. The increased slot depth leads to more slot area and current. On the other hand, it also increases the flux leakage particularly in case of the single sided structures, which impedes further torque production. This is not the case for the YASA machine. Therefore, it is expected that YASA outperforms single sided structure at even lower current densities when more space is permitted in the axial direction. Likewise, for axially shorter designs single sided machines outperform YASA machine in a wider range of current density. This is shown by a second study for a smaller frame with $20 \%$ reduction in the slot depth, Fig. 7, where the YASA structure only barely outperforms the single sided machine at very high current densities.

The 3D FEA model is validated with experimental measurements for the single sided and YASA machine. The prototyped machines are shown in Fig. 9. The back EMF constant obtained at different currents, from measurements as well as 3D FEA, are presented in Table II and show good agreement.

\section{CONCLUSION}

The performance of the YASA machine compared to single sided machines at different loadings is comprehensively examined. The armature reaction, saturation effects, power factor, and torque constant are among the performance indices which are studied. Comparative studies, based on simple analytical equations and experimentally validated 3D finite element analysis indicate that for naturally cooled low to medium speed applications, the performance of the single sided machine is better than that of the YASA topology. On the other hand, for applications requiring a high torque density, which employ forced cooling, the YASA machine may have advantages. It is illustrated that the YASA structure is more suitable where more space for slots in axial direction is available. The studies indicate that the choice of AFPM machine configuration is heavily dependent on application requirements and dimensional specifications.

\section{ACKNOWLEDGMENT}

The support of Regal Beloit Corporation, University of Kentucky, the L. Stanley Pigman endowment and the SPARK program, and ANSYS Inc. is gratefully acknowledged.

\section{REFERENCES}

[1] M. Rosu, P. Zhou, D. Lin, D. M. Ionel, M. Popescu, F. Blaabjerg, V. Rallabandi, and D. Staton, Multiphysics Simulation by Design for Electrical Machines, Power Electronics and Drives. Wiley-IEEE Press, 2017.

[2] C. C. Chan, "Axial-field electrical machines design and applications," IEEE Transactions on Energy Conversion, vol. EC-2, no. 2, pp. 294300, June 1987.

[3] T. J. Woolmer and M. D. McCulloch, "Analysis of the yokeless and segmented armature machine," in 2007 IEEE International Electric Machines Drives Conference, vol. 1, May 2007, pp. 704-708.

[4] W. Fei, P. C. K. Luk, and K. Jinupun, "A new axial flux permanent magnet segmented-armature-torus machine for in-wheel direct drive applications," in 2008 IEEE Power Electronics Specialists Conference, June 2008, pp. 2197-2202.

[5] P. Sergeant, H. Vansompel, and L. Dupre, "Performance and implementation issues considering the use of thin laminated steel sheets in segmented armature axial-flux pm machines," in 2014 International Conference on Electrical Machines (ICEM), Sept 2014, pp. 1363-1369.

[6] B. Zhang, T. Seidler, R. Dierken, and M. Doppelbauer, "Development of a yokeless and segmented armature axial flux machine," IEEE Transactions on Industrial Electronics, vol. 63, no. 4, pp. 2062-2071, April 2016.

[7] A. D. Gerlando, G. M. Foglia, M. F. Iacchetti, and R. Perini, "Parasitic currents in stray paths of some topologies of yasa afpm machines: Trend with machine size," IEEE Transactions on Industrial Electronics, vol. 63, no. 5, pp. 2746-2756, May 2016.

[8] B. Zhang, T. Epskamp, M. Doppelbauer, and M. Gregor, "A comparison of the transverse, axial and radial flux pm synchronous motors for electric vehicle," in 2014 IEEE International Electric Vehicle Conference (IEVC), Dec 2014, pp. 1-6.

[9] N. J. Stannard, J. G. Washington, and G. J. Atkinson, "A comparison of axial field topologies employing smc for traction applications," in 2016 19th International Conference on Electrical Machines and Systems (ICEMS), Nov 2016, pp. 1-6.

[10] D. M. Ionel, M. J. Balchin, J. F. Eastham, and E. Demeter, "Finite element analysis of brushless dc motors for flux weakening operation," IEEE Transactions on Magnetics, vol. 32, no. 5, pp. 5040-5042, Sep 1996.

[11] N. Taran, V. Rallabandi, D. M. Ionel, and G. Heins, "Coreless and conventional axial flux permanent magnet motors for solar cars," IEEE Transactions on Industry Applications, vol. 54, 2018, Accepted for publication. 